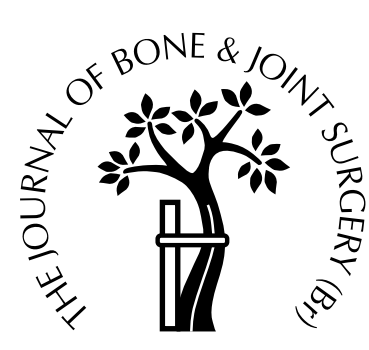

\title{
The posterior interosseous nerve and the posterolateral approach to the proximal radius
}

\author{
J. D. Witt, S. Kamineni \\ From the Middlesex Hospital and University College London \\ Hospitals Trust, London, England
}

W e dissected 21 cadaver elbows to determine the relationship of the posterior interosseous nerve to the posterolateral approach to the elbow and head of the radius. At the distal end of the exposure the first branches at risk, those to extensor carpi ulnaris, were on average $6.0 \pm 1.0 \mathrm{~cm}(4.0$ to 8.4$)$ from the articular surface of the radial head.

When using the posterolateral approach it is important that the interval between extensor carpi ulnaris and anconeus is clearly identified with the forearm fully pronated. The supinator should be released close to its ulnar border. It is safe to expose the proximal radius as far as the distal aspect of the bicipital tuberosity.

J Bone Joint Surg [Br] 1998;80-B:240-2.

Received 4 June 1997; Accepted after revision 5 November 1997

The posterolateral approach to the elbow and the proximal radius between extensor carpi ulnaris (ECU) and anconeus is useful for excision of the radial head, reduction and internal fixation of fractures of it and fixation of some distal humeral fractures. Standard texts warn of the vulnerability of the posterior interosseous nerve (PIN) but give no specific guidelines on safe distal extension, usually stating that this should stop at the level of the annular ligament. ${ }^{1-6}$ This limitation makes the application of plates to the radial head and neck extremely difficult; many surgeons prefer to use a more extensive exposure.

We studied the anatomy of the PIN in this region, to provide more specific guidance on the length of proximal radius that can safely be exposed.

\section{Materials and Methods}

We dissected 21 arms from embalmed adult cadavers. A

J. D. Witt, FRCS, FRCS Orth, Consultant/Honorary Senior Lecturer The Middlesex Hospital and University College London Hospitals Trust, Mortimer Street, London W1N 8AA, UK.

S. Kamineni, FRCS, Specialist Registrar

Chase Farm Hospital, The Ridgeway, Enfield, Middlesex EN2 8JL, UK. Correspondence should be sent to Mr J. D. Witt.

(C1998 British Editorial Society of Bone and Joint Surgery 0301-620X/98/28036\$2.00 standard posterolateral approach extended from the lateral epicondyle of the distal humerus to the posterior border of the shaft of the ulna at about $6 \mathrm{~cm}$ from the tip of the olecranon, with the forearm fully pronated. The interval between the ECU and anconeus was identified and opened to expose the underlying supinator muscle. The proximal fibres of this muscle were then divided with the lateral capsule of the elbow and the annular ligament to expose the head and neck of the radius.

Dissection continued to expose the PIN where it entered the supinator and to follow it distally to expose its more proximal branches as they emerged from within the muscle. These branches were then dissected to determine their relationship to the surgical exposure.

We made measurements from the articular surface of the radial head and the lateral epicondyle of the distal humerus to the most proximal branches of the nerve where these appeared in the distal surgical exposure. We also measured from the lateral epicondyle and radial articular surface to the site of exit of nerve branches from the supinator.

\section{Results}

At the distal end of the posterolateral approach as defined above the first nerves at risk were branches to the ECU and then to extensor digitorum communis. The mean distance from the radial articular surface to the first branch was $6 \pm$ 1.0 (SD) $\mathrm{cm}$ (4.0 to 8.4) and that from the lateral epicondyle of the humerus $8.6 \pm 1.0 \mathrm{~cm}$ (6.5 to 10.9). When the forearm is fully pronated the main part of the PIN is held anteriorly, but at the distal margin of the supinator it divides into multiple branches. The mean distance from the radial articular surface to the branches emerging from the supinator was $5.9 \pm 0.9 \mathrm{~cm} \mathrm{(4.4} \mathrm{to} \mathrm{7.0)} \mathrm{and} \mathrm{from} \mathrm{the} \mathrm{lateral}$ epicondyle $8.2 \pm 1.0 \mathrm{~cm}$ (6.6 to 10.1$)$.

Figure 1 shows the interval between anconeus and the ECU. Figures 2 and 3 show the branches to the ECU more distally, and it is clear that the main nerve and these branches are at greater risk if the supinator is divided over the radius rather than close to its ulnar attachment. Figure 4 shows the general relationship between the PIN, the supinator and the radial neck.

We found that about $6 \mathrm{~cm}$ of the proximal radius could be safely exposed, but this will vary according to the size of the

THE JOURNAL OF BONE AND JOINT SURGERY 

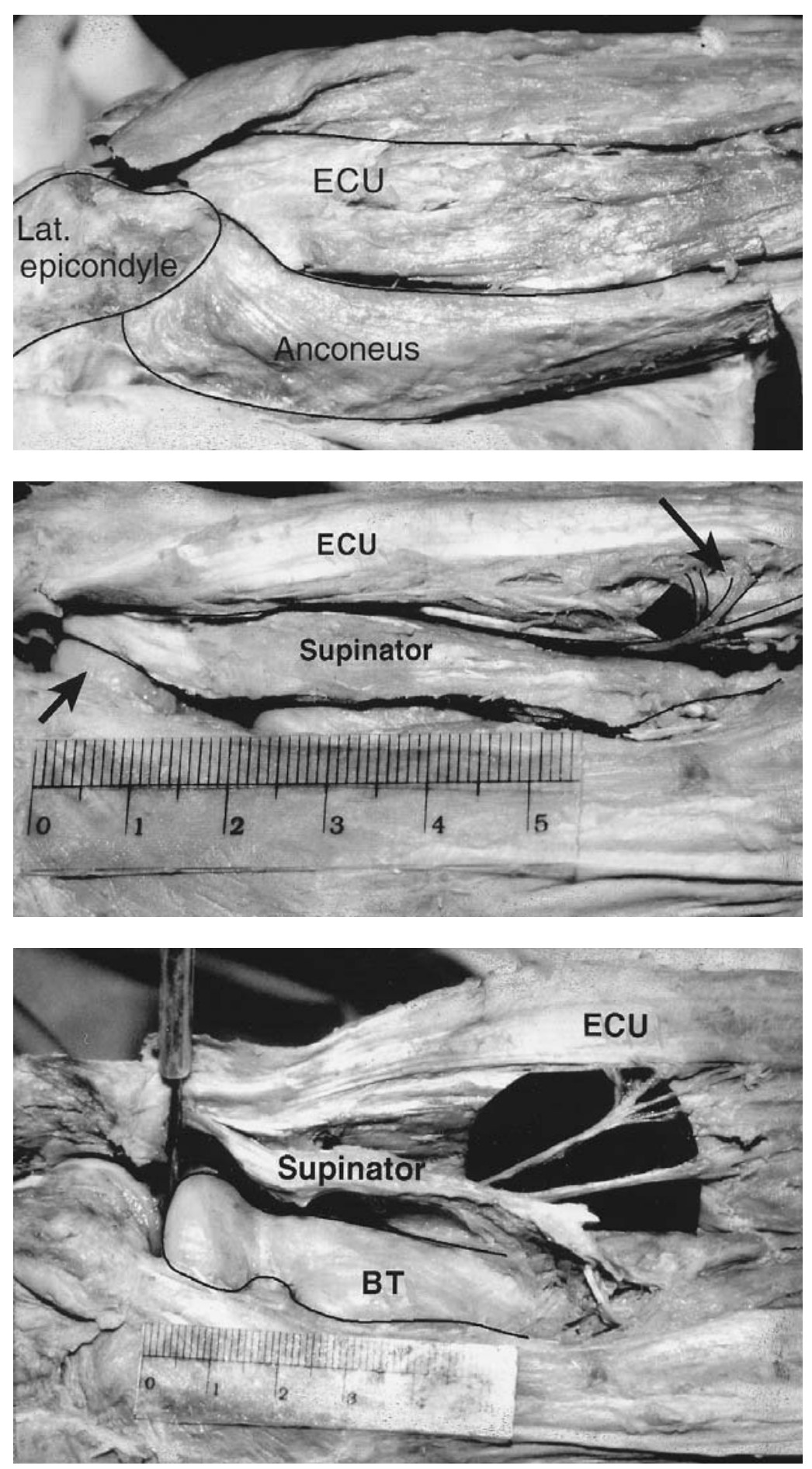

Fig. 1

To show the interval between anconeus and the ECU.
Fig. 2

The ECU has been reflected upwards, and the supinator and annular ligament incised to reveal the head of the radius (short arrow). Branches of the PIN are seen entering the ECU (long arrow).

\section{Fig. 3}

The supinator has been reflected anteriorly from the radius to expose the head, neck and proximal shaft. The bicipital tuberosity (BT) is visible and the nerve supply to the ECU is shown. patient. An anatomical landmark may be more useful, and we found that exposure of the proximal radius was safe as far as the distal extent of the bicipital tuberosity, which is visible in the lower wound when the forearm is fully pronated.

\section{Discussion}

The vulnerability of the PIN to injury from trauma to the proximal radius or surgical approaches is well documented. $^{7-11}$ The proximal third of the shaft of the radius can be exposed anteriorly by the Henry approach, ${ }^{12}$ or posteriorly by that of Thompson. ${ }^{13}$ Both of these exposures allow the PIN to be seen and protected as supinator is reflected from the proximal radius.

The third approach, specifically for the head and neck of the radius, is the posterolateral one between anconeus and the ECU, which is the distal limb of the Kocher approach. ${ }^{14}$ An advantage is that much less dissection is needed to expose the radial head, but a disadvantage is that the PIN is not seen and the surgeon must be clearly aware of its relationship to the 


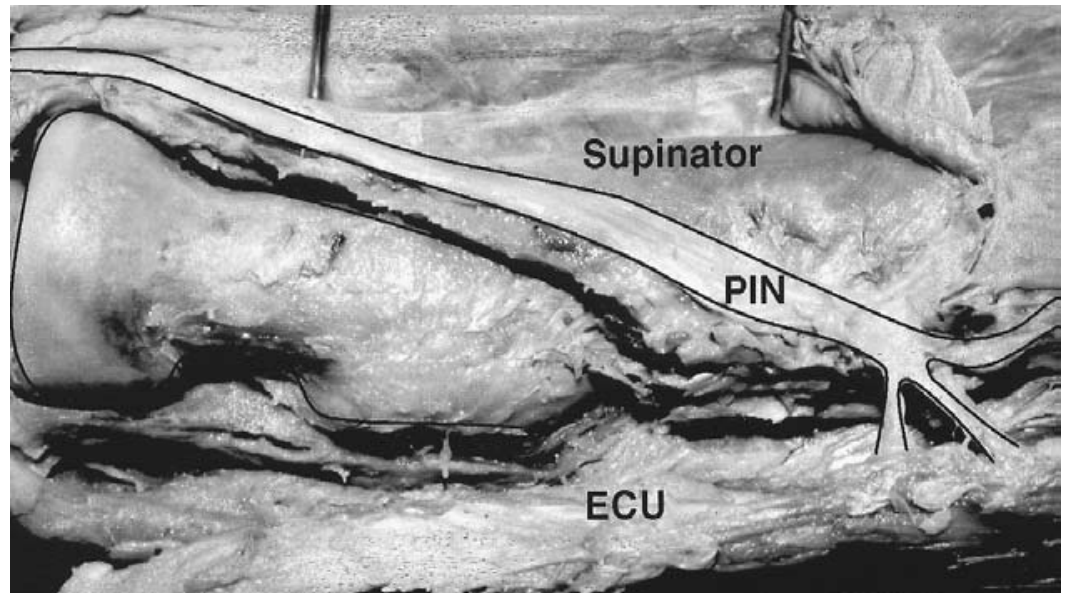

Fig. 4

The superficial belly of supinator has been reflected anteriorly and some of its deep part excised to show the relationship to the PIN and the proximal radius. The ECU has been reflected down to show short branches from the PIN entering it at the distal border of supinator.

proximal radius and the surrounding muscles. This is discussed in most texts on surgical approaches, but there is no clear guidance on how much of the proximal radius can be exposed, and particularly whether it is safe to apply a plate to the radial head or neck through this approach.

The anatomy of the PIN and its branches has been well described. ${ }^{15,16}$ Sunderland ${ }^{16}$ also makes it clear that the nerve divides at the distal margin of the supinator into a complex leash of branches which would be very difficult to repair. Kaplan ${ }^{8}$ described an approach to the proximal radius which uses the interval between extensor carpi radialis brevis and extensor digitorum communis with the forearm in pronation, but any distal extension of this approach puts the branches of the PIN at immediate risk. Strachan and Ellis ${ }^{9}$ used a radiological method on cadaver elbows to show that the PIN moved up to $1 \mathrm{~cm}$ medial to the radius on pronation of the forearm, and recommended this position during operations for excision of the radial head. They focused on protecting the radial nerve during this procedure, but did not address the issue of how much of the proximal radius could safely be exposed. Mekhail et al ${ }^{17}$ studied three different surgical approaches to the proximal radius in 30 cadaver limbs and reported that it was safe to expose about $6 \mathrm{~cm}$ of the proximal radius using a posterolateral approach before undue traction was placed on the branches of the PIN.

We have shown that the posterolateral approach is suitable not only for fixation of fractures of the radial head and neck, but also for the repair of a ruptured biceps tendon as part of the two-incision technique and for resection of a proximal radioulnar synostosis. We recommend the following guidelines to minimise the risk of nerve injury:

1) the forearm should be fully pronated,

2) the interval between the ECU and anconeus must be carefully identified, by recognising the fan-shaped direction of the fibres of anconeus, which are horizontal proximally and more vertical distally,

3) the supinator muscle should be released close to the ulna, and
4) the proximal radius can safely be exposed as far as the distal extent of the bicipital tuberosity of the radius.

We wish to thank the Departments of Anatomy of University College and the Middlesex Hospital Medical School and the Royal Free Hospital Medical School.

No benefits in any form have been received or will be received from a commercial party related directly or indirectly to the subject of this article.

\section{References}

1. Hoppenfeld S, De Boer P. Surgical exposures in orthopaedics. 2nd edition. JB Lippincott Company, 1994:530-9.

2. Ruedi T. Surgical approaches for internal fixation. Springer-Verlag, 1983:44-7.

3. Williams RP, Heckman JD. Contemporary extensile exposures in orthopaedic surgery. Williams and Wilkins, 1997:119-23.

4. Banks SW, Laufman H. An atlas of surgical exposures of the extremities. W R Saunders, 1987:120-5.

5. Tubiana R, McCullough CJ, Masquelet AC. An atlas of surgical exposures of the upper extremity. M Dunitz, 1990:101-7.

6. Colton CL, Hall AJ, eds. Atlas of orthopaedic surgical approaches. Oxford: Butterworth Heinemann Ltd, 1991:79-85.

7. Birch R, Bonney G, Dowell J, Hollingdale J. Iatrogenic injuries of peripheral nerves. J Bone Joint Surg [Br] 1991;73-B:280-2.

8. Kaplan EB. Surgical approach to the proximal end of the radius and its use in fractures of the head and neck of the radius. J Bone Joint Surg 1941;23:86-92.

9. Strachan JCH, Ellis BW. Vulnerability of the posterior interosseous nerve during radial head resection. J Bone Joint Surg [Br] 1971; 53-B:320.

10. Thomas MA, Fast A, Shapiro D. Radial nerve damage as a complication of elbow arthroscopy. Clin Orthop 1987;215:130-1.

11. Tabor OB Jr, Bosse MJ, Sims SH, Kellam JF. Iatrogenic posterior interosseous nerve injury: is transosseous static locked nailing of the radius feasible? J Orthop Trauma 1995;9:427-9.

12. Henry AK. In extensile exposure. 2nd ed. Edinburgh: Churchill Livingstone, 1973:19.

13. Thompson JE. Anatomical methods of approach in operations on the long bones of the extremities. Ann Surg 1918;68:309-29.

14. Kocher T. Textbook of operative surgery. 3rd ed. New York: Macmillan 1911:314-8.

15. Linell EA. The distribution of nerves in the upper limb, with reference to variabilities and their clinical significance. J Anat London 1921;55:79-112.

16. Sunderland S. Metrical and non-metrical features of the muscular branches of the radial nerve. J Comp Neurol 1946;85:93-7.

17. Mekhail AO, Ebraheim NA, Jackson WT, Yeasting RA. Vulnerability of the posterior interosseous nerve during proximal radius exposures. Clin Orthop 1995;315:199-208. 